\title{
Epigenetic Biomarkers in Skin Cancer
}

\author{
Edward S. Greenberg ${ }^{1}$, Kelly K. Chong ${ }^{1}$, Kelly T. Huynh ${ }^{1}$, Ryo Tanaka ${ }^{1}$, and Dave S.B. \\ Hoon $^{1}$ \\ ${ }^{1}$ Department of Molecular Oncology, John Wayne Cancer Institute at Saint John's Health Center, \\ Santa Monica, CA, USA
}

\begin{abstract}
Epigenetic aberrations have been associated with cutaneous melanoma tumorigenesis and progression including dysregulated DNA gene promoter region methylation, histone modification, and microRNA. Several of these major epigenetic aberrations have been developed into biomarkers. Epigenetic (methylation) biomarkers can be detected in tissue and in blood as circulating DNA in melanoma patients. There is strong evidence that biomarkers in cutaneous melanoma will have an important role as companions to therapeutics and overall patient management. Important progress has been made in epigenetic melanoma biomarker development and verification of clinical utility, and this review discusses some of the key current developments and existing challenges.
\end{abstract}

\section{Keywords}

epigenetics; biomarker; methylation; microRNA; melanoma; prognosis

\section{Introduction}

Major skin cancers worldwide predominantly include basal cell carcinoma (BCC), cutaneous melanoma and cutaneous T-cell lymphoma (CTCL). This review will focus specifically on cutaneous melanoma, the most malignant form of skin cancer with the most extensive epigenetic analysis on biomarkers (BMs) conducted to date. Cutaneous malignant melanoma is a highly aggressive disease, comprising less than $5 \%$ of skin cancers but accounting for a majority of the deaths from skin malignancies [1]. Overall, the incidence rates of melanoma have been rising in the United States over the past 10 years, with patient survival dependent on early detection and diagnosis. Patients with metastatic melanoma have a poor prognosis, with 5-year overall survival (OS) for patients with regional or distant metastasis less than $70 \%$ and $20 \%$ respectively, as compared to over $95 \%$ for those with localized disease [2]. In patients with advanced melanoma, although some promising new therapies have recently emerged, a better understanding of the molecular alterations such as genomic and epigenomic aberrations involved in melanoma progression, particularly from

\footnotetext{
(C) 2012 Elsevier Ireland Ltd. All rights reserved.

Requests for reprints: Dr. Dave S.B. Hoon, Dept of Molecular Oncology, John Wayne Cancer Institute at Saint John's Health Center, 2200 Santa Monica Blvd, Santa Monica, CA 90404; Fax: 310-449-5282; hoon@jwci.org.

Conflict of Interest: All authors disclose no financial/commercial conflict of interest.

Publisher's Disclaimer: This is a PDF file of an unedited manuscript that has been accepted for publication. As a service to our customers we are providing this early version of the manuscript. The manuscript will undergo copyediting, typesetting, and review of the resulting proof before it is published in its final citable form. Please note that during the production process errors may be discovered which could affect the content, and all legal disclaimers that apply to the journal pertain.
} 
localized tumors to metastasis, will aid in early detection and development of BMs and future targeted treatment strategies.

Melanoma, like other solid tumors, is thought to arise from a series of genetic and epigenetic events. Genetic aberrations have been identified in the past decade and have potential utility as BMs [3-9]. Recently, multiple studies have revealed that epigenetic events, such as genomic promoter region methylation of $\mathrm{CpG}$ islands, histone modification, and microRNA (miRNA) expression, have been shown to be important regulators of melanoma progression, and that these epigenetic changes can potentially serve as molecular BMs in tumor tissues and in blood as circulating DNA, for diagnosing disease and predicting disease outcome and progression (Figure 1) [10-13].

\section{DNA methylation}

Epigenetics refers to heritable changes in gene expression that are not caused by changes in the genomic DNA sequence. DNA methylation is one of the hallmark epigenetic events most studied in cancers. DNA methylation involves the addition of a methyl group to the 5, carbon of a cytosine ring located 5' to a guanosine base in a CpG dinucleotide and is catalyzed by DNA methyltransferases (DNMTs) [1]. These CpGs are often clustered in short CpG-rich DNA stretches; deemed CpG islands, and the majority are found in the promoter region of genes [14]. Methylation events of promoter regions have been strongly implicated in cutaneous melanoma progression $[10,12]$. Hypermethylation of $\mathrm{CpG}$ islands in the promoter region leads to gene silencing through the inhibition of transcription or via recruitment of chromatin remodeling co-repressor complexes [15]. Silencing of tumor suppressor genes or tumor-related genes (TRGs) can occur during melanoma development or later in advanced stage melanoma [12,16]. Epigenetic inactivation of multiple TRGs has been implicated in the establishment of malignancy and throughout stages of melanoma progression and metastasis [1,14]. Many of these genes are involved in cell cycle control, cell signaling, migration and invasion, apoptosis, angiogenesis, and metastasis [14,17]. At the same time there are TRGs that are activated in melanoma that are silenced in melanocytes. This transcription activation can be attributed to hypomethylation of the $\mathrm{CpG}$ islands in the promoter region and histone modifications.

\subsection{DNA methylation detection techniques}

One of the challenges in evaluating the DNA methylation status of genes is the fact that several techniques exist for evaluation of $\mathrm{CpG}$ island methylation. A recent review by Laird provides an excellent overview of the main principles of DNA methylation analysis, dividing these techniques into various types of pretreatment (enzyme digestion, affinity enrichment, sodium bisulfite) followed by different analytical steps (locus-specific analysis, gel-based analysis, array-based analysis, and next-generation sequencing-based analysis) [18]. Technique selection depends on the quality and quantity of input DNA needed, purity and type of tissue or fluid DNA is being extracted from, extent of genome coverage, and overall assay reproducibility, sensitivity, specificity, accuracy, and quantification. Moreover, despite advances in this field and development of multiple platforms for studying genomic methylation, uniformity and standardization remain significant issues in evaluating and comparing results.

Sodium bisulfite modification (SBM) of genomic DNA is one of the most well-utilized techniques for assessing $\mathrm{CpG}$ methylation status, based on the modification of genomic unmethylated cytosines to uracil $[19,20]$. Bisulfite conversion requires DNA denaturation before treatment and subsequent purification to remove the sodium bisulfite, thus causing substantial DNA degradation and often times requiring a large amount of high-purity input DNA. Other limitations of SBM include incomplete bisulfite conversion and differential 
PCR efficiency for methylated versus unmethylated sequences [18]. Bisulfite-based DNA methylation analysis is currently regarded as the "gold standard" and offers the advantage of quantitative assessment, detection sensitivity and the ability to analyze a wide variety of samples, though it is limited by the amount of DNA isolated from SBM as described above. The most commonly used SBM assays for assessing epigenomic BMs include: bisulfite sequencing, bisulfite pyrosequencing, combined bisulfite restriction analysis (CoBRA), methylation-specific realtime PCR (MSP), and gel electrophoresis $[15,21]$. The advantages of MSP include that it can be performed on very small quantities of DNA, such as that from paraffin-embedded tissues or free-circulating DNA in blood, and its products can be assessed by various platforms including gel electrophoresis, capillary array electrophoresis (CAE), MassARRAY, or real-time quantitative MSP as BMs [22]. CAE, MassARRAY and real-time MSP offers the ability to quantitatively evaluate a promoter region; moreover, with the MassARRAY method, one can determine the specific $\mathrm{CpG}$ island that best correlates with gene expression [22].

A newer approach of BM assessment is methylation-sensitive restriction enzyme digestion assays, based on the sensitivity of sequence-specific restriction enzymes that can recognize methylated cytosine within their cleavage recognition site. Although a cost effective and sensitive approach when coupled with PCR following enzyme digestion, this technique is limited to the analysis of $\mathrm{CpG}$ sites located within the enzyme recognition site(s) and is prone to false-positive results secondary to incomplete enzyme digestion. Affinity enrichment assays use antibodies specific for methylated CpGs or methyl-binding proteins with affinity for methylated genomic DNA. These methods allow for genome-wide assessment of DNA methylation but are limited by lack of specificity in areas of low CpG density and cannot be used to obtain information on individual CpG sites [16,18].

Another major challenge is identifying the key regulator(s) $\mathrm{CpG}$ islands in the promoter region. There can be more than one gene or a specific repetitive sequence region that controls mRNA transcription. It is also possible that no $\mathrm{CpG}$ regulatory site exists in a gene promoter region. The majority of promoter region regulatory $\mathrm{CpG}$ sites are near the openreading frame. It takes methodical analysis of $\mathrm{CpG}$ region sequencing in conjunction with mRNA expression to determine key regulatory sites. Studies may often report hyper- or hypo-methylation in the gene promoter region that plays little role in affecting respective gene transcription.

\subsection{DNA methylation BMs for diagnosis and prognosis}

Aberrantly methylated melanoma TRGs can serve as BMs for early diagnosis of cancer, evaluation of cancer progression, and as prognostic indicators in melanoma patients. Our group identified and verified the inactivation of RAS association domain family protein $1 \mathrm{~A}$ (RASSF1A), a tumor suppressor gene, in melanoma [23]. RASSF1A is involved in the regulation of apoptosis, migration, and metastasis [1]. An increase in RASSF1A methylation positively correlates with advancing tumor stage, suggesting that RASSF1A may be a useful $\mathrm{BM}$ of melanoma progression [12]. Separately, RASSF1A methylation has also been reported in approximately $50 \%$ of Merkel cell carcinoma (MCC) cases in a study of 83 tumors [24].

Tanemura et al. examined the methylation status of $\mathrm{CpG}$ islands in the promoter region of six TRGs involved in melanoma progression (WIF1, TFPI2, RASSF1A, RAR- $\beta 2$, SOCS1, and GATA4) and a panel of methylated-in-tumor (MINT) non-coding genomic repeat sequences (MINT1, MINT2, MINT3, MINT12, MINT17, MINT25, and MINT31) to determine whether there exists a clinically significant $\mathrm{CpG}$ island methylator phenotype (CIMP), or a distinct methylation pattern of TRGs, related to melanoma progression [12]. MINT loci are hypermethylated CpG sites located in non-coding DNA regions that have 
been reported in gastrointestinal cancer and correlated with hypermethylation of TRGs with a defined CIMP $[25,26]$. Comparing the methylation status of melanoma primary and metastasis, they found that an increase in hypermethylation of WIF1, TFPI2, RASSF1A, and SOCS1 was seen with increasing clinical tumor stage [12]. Moreover, there was a significant association between the methylation status of MINT17 and MINT31 and TRGs, supporting the existence of a CIMP that is associated with advancing clinical stage in melanoma patients and suggests a worse prognosis in patients with hypermethylation of these genes.

DNA promoter methylation analysis can be successfully performed in both tissue and fluids. The assessment of these BMs as cell-free circulating nucleic acids (cf-CNAs) in blood provide a non-invasive and clinically useful way to repetitively monitor patients compared to tissue biopsy. Our group was one of the first to report the prognostic utility of combining detection of circulating tumor cells (CTCs) with assessment of methylated blood DNA BMs [27]. Matched pairs of nucleated cells from whole blood and serum specimens from 50 AJCC stage IV melanoma patients were assessed for three mRNA CTC BMs (MART-1, GalNAc-T, and MAGE-A3) and two methylated DNA BMs (RASSF1A and RAR- $\beta 2$ ). The CTC BMs were significantly associated with the presence of methylated cf-CNA and the presence of both was an indicator of poor OS under biochemotherapy (BC) [27]. This suggested that CTC may be a significant source of circulating methylated DNA. We have demonstrated that cf-CNA as methylated TRGs such as RASSF1A, MGMT, RAR $\beta 2$, and ERa can be used as epigenomic BMs for monitoring cutaneous melanoma and have prognostic utility (Figure 2) [28]

Epigenomic BMs can also potentially be used to monitor patient treatment response. Mori et al. demonstrated, in serum DNA of stage IV melanoma, that circulating methylated RASSF1A was significantly less frequent for BC responders than nonresponders, indicating that increased methylation correlates not only with a worse prognosis but also can be used to monitor development of resistance to therapy. In a study of stage IV melanoma patients undergoing $\mathrm{BC}$ with tamoxifen, serum estrogen receptor alpha (ER-a) methylation was an unfavorable prognostic factor and a negative predictor of overall and progression-free survival in patients treated with BC (Figure 3) [10].

\subsection{DNA global hypomethylation}

Global DNA hypomethylation can lead to chromosomal instability, activation of endogenous retroviral elements, and reactivation of genes with oncogenic activity, such as cancer testis genes, for example, the MAGE (melanoma antigen) family [17]. In malignant melanoma, aberrant expression of MAGE genes occurs secondary to promoter hypomethylation [29]. It has also been observed that methylation levels of genomic repetitive sequences such as long interspersed nuclear element-1 (LINE-1) are representative of global methylation status [16]. In patients with Stage IIIC cutaneous melanoma, Sigalotti et al., identified LINE-1 methylation as a molecular marker of prognosis with patients demonstrating LINE-1 hypomethylation having a significantly better OS compared to those with hypermethylated LINE-1 sequences [30]. However, discordance between blood LINE-1 status and melanoma tumors was reported, and the studies will need to be verified.

\subsection{Mechanisms of melanoma TRG methylation}

DNMT1 is associated with the maintenance of established DNA methylation patterns; whereas DNMT3A and DNMT3B have been implicated in the generation of de novo methylation patterns at previously unmethylated CpGs [15]. A recent study by Nguyen et al. demonstrated that DNMT3A and DNMT3B protein expression are significantly correlated with increasing AJCC stage and that high expression of DNMT3B by immunohistochemistry (IHC) staining was significantly correlated with worse OS in AJCC 
stage III melanoma patients by multivariate analysis ( $\mathrm{p}=0.004)$ [11]. DNMT3 can be a potential BM for melanoma progression. Significant correlation of these events was associated with RASSF1A promoter methylation. This indicated that significant changes in mechanisms involved in epigenomic regulation of melanoma are occurring during clinical progression. Several DNMT inhibitors have been investigated in clinical trials, most notably 5-aza-2'-deoxycytidine, also known as decitabine [1]. However, there is concern for drug toxicity as the lack of specificity of these demethylating agents may lead to global hypomethylation and potentially activation of tumor proto-oncogenes [17]. This area still remains of major interest to pharmaceuticals for development of less toxic drugs with greater specificity towards cancer.

Temozolomide (TMZ), an orally available drug, has been used to treat melanoma patients with metastatic disease [31]. TMZ depletes levels of methylguanine methyltransferase (MGMT), a DNA repair enzyme, and TMZ sensitivity has been correlated with methylation of the MGMT promoter [32]. In a phase II study, Rietschel et al., treated unresectable stage III and stage IV melanoma patients with extended-dose TMZ and assessed their clinical response in conjunction with MGMT promoter methylation status. They found that MGMT promoter methylation level more than $25 \%$ positively correlated with a partial clinical response.

Overall, these epigenetic changes in melanoma can serve as potential BMs for prognosis and prediction. Development of clinically efficient tests will be important in assisting with decision making in treatment management. Epigenomics in melanoma offer new potential BMs for tumor and blood while at the same time offering potential targets for therapy.

\section{3. microRNA}

miRNAs are evolutionarily conserved, endogenous, non-coding RNA transcripts of $\sim 22$ nucleotides in length that serve to temporally and spatially regulate biological function [33]. miRNA are considered an epigenomic mechanism that can have normal regulatory function but also can have negative influence when dysregulated, particularly in cancer progression as in melanoma. They are derived from non-coding intergenic or intronic regions of DNA that, once in their mature form, interfere with protein translation from mRNA transcripts. miRNA can preferentially bind with the 3' untranslated region (UTR) of mRNA transcripts to inhibit translation or degrade the mRNA transcript before translation can take place [34].

miRNA can modulate biological functions, e.g., cell cycle, proliferation, apoptosis, and angiogenesis, which, if aberrantly regulated, can lead to malignancy [35]. For example, miR-221/222 was found to interfere with c-KIT and p27, causing dysregulation of the cell cycle during the progression of melanoma [36]. miRNA regulation may influence the microenvironment, and can contribute to tumor cell invasion, migration and metastasis [37]. miRNA regulation of protein coding genes is, therefore, an essential regulatory element in normal biological development and function.

Deregulated miRNA expression may serve as diagnostic or prognostic BM in cutaneous melanoma (see Table 1 for a list of recent miRNA melanoma studies). In the previously mentioned Nguyen et al. study, DNA methyltransferases DNMT3A and DNMT3B were shown to be regulated by miR-29c in melanoma [11]. This mechanism was first demonstrated earlier in lung malignancy [38], thus implying that the epigenetic pathways currently associated with other cancers may be applicable in skin cancers as well. In addition to the demonstration of functional association in melanoma, both miR-29c and DNMT3B were found to be significantly independent prognostic predictors of OS in Stage III melanoma patients through multivariate analysis including common melanoma prognostic 
factors. This also shows that multiple epigenetic factors within a single pathway can function as independent BMs, supporting both the functional and prognostic value of the discovery of epigenetic pathways.

As a potential BM of progression and outcome, Gaziel-Sovran et al. [37] showed that increased expression of miR-30b/30d downregulated GALNT7 leading to enhanced migration and lowered immunosuppressive features. They were able to identify a novel immunosuppressive role for GALNT7 as a direct regulator of immunosuppressive cytokine IL-10. Interestingly, this immunosuppressive effect was also found at the site of metastasis, suggesting a possible long range of deregulation and control of immunosuppression in cancer that extends beyond the microenvironment. In terms of prognostic BM potential, expression levels of these miRNAs have been correlated with transition from primary to metastasis, and to recurrence and OS. However, the specificity and significance of these miRNAs have yet to be verified in large sample sizes and multicenter studies. One of the major drawbacks of miRNA is that they target many types of genes and can have multiple functions in both normal and tumor tissues [see www.miRwalk.com website]. Other major problems in miRNA are that miRNA assays are not always controlled, properly quantified, or uniformly reported.

Grignol, et al. characterized deregulated miRNA expression with a change in tissue from benign nevi status to borderline melanocytic lesions. The authors demonstrated a relationship between upregulation of $m i R-21$ and $m i R-155$ and malignant phenotypical changes (increased mitotic activity and lesion depth, respectively). A significant number of patients whose tissue was shown to overexpress these two miRNAs progressed to develop sentinel lymph node metastasis. These miRNAs may therefore serve to supplement and further characterize traditional methods of melanoma analysis such as Breslow depth and the mitotic index [39].

Interestingly, $\mathrm{CpG}$ island methylation has been shown to regulate expression of miR-375 in Stage III melanoma cell lines [40] through treatment of cell lines with demethylating agents 5AzadC and 4-PBA. The methylation state of the miR-375 CpG islands was significantly greater in Stage II or III melanoma cell lines when compared to Stage I melanoma or benign melanocytes, which demonstrates a potential utility for miR-375 methylation status as a BM for progression. The study additionally demonstrated a functional association of miR-375 with inhibition of proliferation and invasion of melanoma cell lines, which provides rationale for its role in progression.

Other studies have demonstrated regulation of multiple miRNAs by methylation [41], with a group recently demonstrating $\mathrm{CpG}$ island methylation regulation of miR-34b [42]. Increased methylation frequency was shown in Stage III and IV melanoma cell lines when compared with normal melanocytes, keratinocytes, and Stage I and II melanoma cell lines, indicating miR-34b expression as a possible marker for metastatic disease.

\subsection{Assay for circulating miRNA}

Assays for circulating miRNA have added a promising new platform in the search for BMs. Circulating assays offer advantages over other BM assessment procedures in the clinical setting. Tissue biopsy can impose the burden of morbidity risks that accompany any invasive procedure [43], failure rate in small tumors [44], relative expense, and the inherent limitation of available or accessible sample. Further, circulating miRNA appear to exhibit superior stability over tissue derived species $[45,46]$. Serial bleeds can serve as the source of samples used to monitor changes in miRNA expression throughout a patient's treatment course. miRNA circulating in blood derivatives, including whole blood, plasma, and serum, have been shown to be differentially expressed in a variety of cancers versus normal patients 
[47-51]. A recent study of $m i R-221$ in the circulation [52], using serum from 90 clinically well characterized patients along with 8 postoperative recurrence sera, demonstrated its potential as a non-invasive detection BM capable of distinguishing between in situ and invasive melanoma, and confirming prior miR-221/222 studies in tissue [36].

\subsection{Challenges}

Overall challenges to the BM use of miRNA remain, nevertheless. Conflicting results are widely reported and study variations make comparisons somewhat difficult. Limitations of miRNA BM studies include the fact that individual study samples may be limited and not always well characterized in terms of clinicopathological factors, microdissection is not always used for precise tissue sample acquisition, and interpretation of PCR results and choice in reference markers vary [53]. The diversity of assay platforms available also presents an additional opportunity for discordance [54]. Several detailed reviews of the more general issues that surround the interpretation of study results have recently been published [55-57].

Challenges to the circulating miRNA assay remain as well. Unlike the direct tissue assay, other tissues besides tumor are known to release miRNA into the circulation and may influence circulating miRNA assay results [51]. As with tissue assays, platforms, methods, and results are variable in publication [58]. Further, controls in circulating miRNA as BMs remain a critical problem [56].

While the promise of a non-invasive bodily fluid assay for circulating miRNA is appealing, additional challenges arise from the unique nature of the assay and the source of sample, such as differences in expression that are related to the particular blood fraction and the method of miRNA secretion [59]. Yet despite these obstacles, in melanoma these miRNA in tissues and blood are potential epigenomic BMs that should be further exploited.

\section{Histones}

Histones are paired core protein octamers around which DNA chromatin are organized in a plastic architecture of $\sim 147 \mathrm{bp}$ nucleosomes. Third dimensional conformation of the nucleosome can be altered by a variety of catalytic enzymes that can deposit or remove covalent molecules on the $\mathrm{n}$-terminal histone tail residues that extends from each histone, in order to repress RNA transcription through a closed formation (heterochromatin) or to allow transcription through an open formation (euchromatin). Molecule depositions can also interact with other direct DNA methylating agents, a form of epigenetic crosstalk, to further mediate transcription status in relation to other epigenetic and biological expression programs. In melanoma these relations may become deranged, leading to tumorigenesis [60].

\subsection{Histone Modification in Melanoma}

The study of histone modification (methylation, acetylation, phosphorylation, sumoylation, uquitinylation) $[61,62]$ is a form of epigenomics. This is a field still in its infancy particularly as BMs. However, preliminary studies suggest histone types and modifications may be potential BMs of gene regulation. The lysine tail of each of the four main histones (H2A, H2B, H3 and H4) can accommodate many different arrangements of the same set of covalent molecules, with different regulatory outcomes depending on the particular modification pattern [60]. In addition, entire histones may be substituted with variants that come with preconfigured histone tail patterns $[63,64]$.

Histone changes have been primarily linked to the ability for malignant melanoma to escape the senescent phenotype that characterizes benign nevi and normal tissue. Melanoma cells 
are able to escape the senescent phenotype ordinarily imposed on DNA damaged cells by the p53/p14ARF pathway. Studies have shown that histone marks and the expression level of histone modifying enzymes are correlated with uncontrolled proliferation in melanoma $[15,65]$.

Bachmann IM et al. reported that higher EZH2 expression was associated with thicker primary melanomas and Clark's invasion level V. Interestingly, higher EZH2 expression was associated with loss of p16 expression and strong expression of Cyclin D1 [66]. They also reported that 5-year survival in patients with high EZH2 expression was 48\%, compared with $71 \%(\mathrm{p}=.032)$ among the cases with low EZH2 expression, suggesting prognostic BM potential. EZH2 has been shown to downregulate expression of tumor suppressor Rap1GAP [67] and p21 in melanoma [68].

Histone acetylation has been closely studied in tissue, cell line and animal models of melanoma where it has been shown to correlate with senescence $[69,70]$. This has led to multiple therapeutic trials for HDACi, including in melanoma (Vorinostat, MS-275, Pivanex, Valproic Acid, and Panobinostat), though many have shown limited benefit entailing significant side effects. However, clinical trials are still ongoing. Completion of a multicenter phase II trial of MS-275, an HDAC1/3 inhibitor, in patients with unresectable metastatic melanoma who have received at least one other systemic treatment [71] showed well-tolerated, long-term tumor stabilizations, but no objective responses in pretreated metastatic melanoma. Despite the development and pursuit of HDACi in clinical trials, expression of acetylation or acetylation enzymes has yet to be tied to diagnostic or prognostic outcomes in a robust assay.

Development of histone BMs in melanoma has been challenged by the absence of an efficient, robust assay method. Indirect measurement of histone status by methods such as IHC and chromatin immunoprecipitation (ChIP) are less than quantitative and, in the case of ChIP, are subject to wide procedural variation between labs, with multiple steps that are prone to error and requiring several days at the bench per assay [72]. Mass spectrometry, though potentially quantitative, likewise contains many processing steps that have seen difficulty in replication between labs [73]. No platform as yet provides a direct measure of histone enzyme activity at the lysine residue. These represent challenges yet to be resolved in the effort to establish epigenetic histone BMs in melanoma [74].

\section{Epigenetic Studies in Non-melanoma Skin Cancers}

We will briefly mention other skin cancers as there have been limited studies on epigenetic BMs for other skin cancer types. BCC and squamous cell carcinoma (SCC) represent the majority of skin cancer cases, with over 2 million cases treated in 2006 [75]. However, these skin cancer types are less aggressive than melanoma and are often curable by surgical excision. As a result, BM work on BCC and SCC has been minimal. In BCC, methylation of the FHIT promoter has been demonstrated [76], while methylation in the PTCH gene was shown to likely play only a minor role in carcinogenesis [77]. Other rarer forms of skin cancer, such as CTCL and its variants [78] have studies that confirmed repression of BCL7a, PTPRG, TP73, and FAS through methylation [79-81]. MCC [82] demonstrated p14ARK (encoding tumor suppressor p14) methylation in $42 \%$ of 19 tumor samples [83]. Studies regarding application of these epigenetic events as BMs, however, have seen limited use due to the rare nature of CTCL and MCC.

\section{Conclusions}

The development of epigenetic BMs for the diagnosis and prognosis of cutaneous melanoma continues to be promising, yet challenging. BM validation is founded upon robust, accurate 
assays that, in turn, depend on transparency and detailed standard operating procedures abiding by state and national regulatory guidelines that deliver well-characterized qualitative and quantitative results that are meaningful to clinical outcomes. REMARK guidelines [84], were developed to help researchers deliver these objectives, facilitating the comparison of results between publications that study the same candidate BM.

Melanoma BM investigations do not always meet REMARK criteria, and results often appear to conflict between studies and even within the same study. This is evident in all assay platforms and within all areas of epigenetic BM research. Omissions of BM studycritical information include patient treatment prior to sample acquisition, sample preparation and handling, quantitative confirmation for qualitative assays, hazard ratios, confidence intervals and receiver operating characteristic (ROC) curves for specificity and sensitivity of the BM.

Challenges that accompany specific histone, methylation, and miRNA assays have been cited above. Quantitative realtime PCR may generally be expected to deliver the accuracy, robustness, and precision that can validate miRNA and methylation qPCR assays in largescale studies, yet one must be careful in result interpretations. MIQE guidelines for a consistent qPCR assay have also been developed that, along with REMARK guidelines, should serve to facilitate the reporting, discovery and validation of clinically useful BMs [85]. As assays and techniques for epigenomic BMs become standardized, the development of new and reliable melanoma BMs will be made possible in the near future.

\section{Acknowledgments}

This work was supported by the Dr. Miriam and Sheldon G. Adelson Medical Research Foundation, Melanoma Research Alliance, and P01 CA012582 and P01 CA029605 from the National Institutes of Health, National Cancer Institute. The content is solely the responsibility of the authors and does not necessarily represent the official view of the National Cancer Institute or the National Institutes of Health.

\section{Abbreviations}

$\begin{array}{ll}\text { BC } & \text { Biochemotherapy } \\ \text { BCC } & \text { Basal cell carcinoma } \\ \text { BM } & \text { Biomarker } \\ \text { SBM } & \text { Sodium bisulfite modification } \\ \text { CAE } & \text { Capillary Array Electrophoresis } \\ \text { cf-CNA } & \text { cell-free circulating nucleic acid } \\ \text { ChIP } & \text { chromatin immunoprecipitation } \\ \text { CIMP } & \text { CpG Island Methylator Phenotype } \\ \text { CoBRA } & \text { Combined Bisulfite Restriction Analysis } \\ \text { CTC } & \text { Circulating Tumor Cell } \\ \text { CTCL } & \text { Cutaneous T-cell Lymphoma } \\ \text { DNMT } & \text { DNA Methyltransferase } \\ \text { IHC } & \text { immunohistochemistry } \\ \text { LINE-1 } & \text { Long Interspersed Nuclear Element-1 } \\ \text { MCC } & \text { Merkel cell carcinoma }\end{array}$




$\begin{array}{ll}\text { MINT } & \text { Methylated-in-tumor } \\ \text { miRNA } & \text { micro-RNAs } \\ \text { MSP } & \text { Methylation-specific realtime PCR } \\ \text { OS } & \text { Overall Survival } \\ \text { PCR } & \text { Polymerase Chain Reaction } \\ \text { ROC } & \text { Receiver Operating Characteristics } \\ \text { SCC } & \text { Squamous cell carcinoma } \\ \text { TMZ } & \text { Temozolomide } \\ \text { TRG } & \text { Tumor-related Genes } \\ \text { UTR } & \text { Untranslated Region }\end{array}$

\section{References}

1. Schinke C, Mo Y, Yu Y, Amiri K, Sosman J, Greally J, et al. Aberrant DNA methylation in malignant melanoma. Melanoma Res. 2010; 20:253-65. [PubMed: 20418788]

2. Balch CM, Gershenwald JE, Soong SJ, Thompson JF, Atkins MB, Byrd DR, et al. Final version of 2009 AJCC melanoma staging and classification. J Clin Oncol. 2009; 27:6199-206. [PubMed: 19917835]

3. Chatzinasiou F, Lill CM, Kypreou K, Stefanaki I, Nicolaou V, Spyrou G, et al. Comprehensive field synopsis and systematic meta-analyses of genetic association studies in cutaneous melanoma. J Natl Cancer Inst. 2011; 103:1227-35. [PubMed: 21693730]

4. Dahl C, Guldberg P. The genome and epigenome of malignant melanoma. APMIS. 2007; 115:1161-76. [PubMed: 18042149]

5. Goto Y, Koyanagi K, Narita N, Kawakami Y, Takata M, Uchiyama A, et al. Aberrant fatty acidbinding protein-7 gene expression in cutaneous malignant melanoma. J Invest Dermatol. 2010; 130:221-9. [PubMed: 19587692]

6. Taback B, O'Day SJ, Boasberg PD, Shu S, Fournier P, Elashoff R, et al. Circulating DNA microsatellites: molecular determinants of response to biochemotherapy in patients with metastatic melanoma. J Natl Cancer Inst. 2004; 96:152-6. [PubMed: 14734706]

7. Ray PS, Wang J, Qu Y, Sim MS, Shamonki J, Bagaria SP, et al. FOXC1 is a potential prognostic biomarker with functional significance in basal-like breast cancer. Cancer Res. 2010; 70:3870-6. [PubMed: 20406990]

8. Tanaka R, Koyanagi K, Narita N, Kuo C, Hoon DS. Prognostic molecular biomarkers for cutaneous malignant melanoma. J Surg Oncol. 2011; 104:438-46. [PubMed: 21557225]

9. Kitago M, Martinez SR, Nakamura T, Sim MS, Hoon DS. Regulation of RUNX3 tumor suppressor gene expression in cutaneous melanoma. Clin Cancer Res. 2009; 15:2988-94. [PubMed: 19336521]

10. Mori T, Martinez SR, O'Day SJ, Morton DL, Umetani N, Kitago M, et al. Estrogen receptor-alpha methylation predicts melanoma progression. Cancer Res. 2006; 66:6692-8. [PubMed: 16818643]

11. Nguyen T, Kuo C, Nicholl MB, Sim MS, Turner RR, Morton DL, et al. Downregulation of microRNA-29c is associated with hypermethylation of tumor-related genes and disease outcome in cutaneous melanoma. Epigenetics. 2011; 6:388-94. [PubMed: 21081840]

12. Tanemura A, Terando AM, Sim MS, van Hoesel AQ, de Maat MF, Morton DL, et al. CpG island methylator phenotype predicts progression of malignant melanoma. Clin Cancer Res. 2009; 15:1801-7. [PubMed: 19223509]

13. Schwarzenbach H, Hoon DS, Pantel K. Cell-free nucleic acids as biomarkers in cancer patients. Nat Rev Cancer. 2011; 11:426-37. [PubMed: 21562580]

14. Rothhammer T, Bosserhoff AK. Epigenetic events in malignant melanoma. Pigment Cell Res. 2007; 20:92-111. [PubMed: 17371436] 
15. Sigalotti L, Covre A, Fratta E, Parisi G, Colizzi F, Rizzo A, et al. Epigenetics of human cutaneous melanoma: setting the stage for new therapeutic strategies. J Transl Med. 2010; 8:56. [PubMed: 20540720]

16. Fazzari MJ, Greally JM. Introduction to epigenomics and epigenome-wide analysis. Methods Mol Biol. 2010; 620:243-65. [PubMed: 20652507]

17. Howell PM Jr, Liu S, Ren S, Behlen C, Fodstad O, Riker AI. Epigenetics in human melanoma. Cancer Control. 2009; 16:200-18. [PubMed: 19556960]

18. Laird PW. Principles and challenges of genomewide DNA methylation analysis. Nat Rev Genet. 2010; 11:191-203. [PubMed: 20125086]

19. Jones PA, Baylin SB. The fundamental role of epigenetic events in cancer. Nat Rev Genet. 2002; 3:415-28. [PubMed: 12042769]

20. Jones PA, Baylin SB. The epigenomics of cancer. Cell. 2007; 128:683-92. [PubMed: 17320506]

21. Tollefsbol TO. Advances in epigenetic technology. Methods Mol Biol. 2011; 791:1-10. [PubMed: 21913067]

22. Hoon DS, Ferris R, Tanaka R, Chong KK, Alix-Panabieres C, Pantel K. Molecular mechanisms of metastasis. J Surg Oncol. 2011; 103:508-17. [PubMed: 21480243]

23. Hoon DS, Spugnardi M, Kuo C, Huang SK, Morton DL, Taback B. Profiling epigenetic inactivation of tumor suppressor genes in tumors and plasma from cutaneous melanoma patients. Oncogene. 2004; 23:4014-22. [PubMed: 15064737]

24. Helmbold P, Lahtz C, Enk A, Herrmann-Trost P, Marsch W, Kutzner H, et al. Frequent occurrence of RASSF1A promoter hypermethylation and Merkel cell polyomavirus in Merkel cell carcinoma. Mol Carcinog. 2009; 48:903-9. [PubMed: 19326371]

25. Kusano M, Toyota M, Suzuki H, Akino K, Aoki F, Fujita M, et al. Genetic, epigenetic, and clinicopathologic features of gastric carcinomas with the $\mathrm{CpG}$ island methylator phenotype and an association with Epstein-Barr virus. Cancer. 2006; 106:1467-79. [PubMed: 16518809]

26. Toyota M, Ahuja N, Ohe-Toyota M, Herman JG, Baylin SB, Issa JP. CpG island methylator phenotype in colorectal cancer. Proc Natl Acad Sci U S A. 1999; 96:8681-6. [PubMed: 10411935]

27. Koyanagi K, Mori T, O'Day SJ, Martinez SR, Wang HJ, Hoon DS. Association of circulating tumor cells with serum tumor-related methylated DNA in peripheral blood of melanoma patients. Cancer Res. 2006; 66:6111-7. [PubMed: 16778184]

28. Mori T, O'Day SJ, Umetani N, Martinez SR, Kitago M, Koyanagi K, et al. Predictive utility of circulating methylated DNA in serum of melanoma patients receiving biochemotherapy. J Clin Oncol. 2005; 23:9351-8. [PubMed: 16361635]

29. van Doorn R, Gruis NA, Willemze R, van der Velden PA, Tensen CP. Aberrant DNA methylation in cutaneous malignancies. Semin Oncol. 2005; 32:479-87. [PubMed: 16210089]

30. Sigalotti L, Fratta E, Bidoli E, Covre A, Parisi G, Colizzi F, et al. Methylation levels of the "long interspersed nucleotide element-1" repetitive sequences predict survival of melanoma patients. J Transl Med. 2011; 9:78. [PubMed: 21615918]

31. Middleton MR, Grob JJ, Aaronson N, Fierlbeck G, Tilgen W, Seiter S, et al. Randomized phase III study of temozolomide versus dacarbazine in the treatment of patients with advanced metastatic malignant melanoma. J Clin Oncol. 2000; 18:158-66. [PubMed: 10623706]

32. Rietschel P, Wolchok JD, Krown S, Gerst S, Jungbluth AA, Busam K, et al. Phase II study of extended-dose temozolomide in patients with melanoma. J Clin Oncol. 2008; 26:2299-304. [PubMed: 18467721]

33. Pasquinelli AE, Ruvkun G. Control of developmental timing by micrornas and their targets. Annu Rev Cell Dev Biol. 2002; 18:495-513. [PubMed: 12142272]

34. Davis BN, Hata A. microRNA in Cancer---The involvement of aberrant microRNA biogenesis regulatory pathways. Genes Cancer. 2010; 1:1100-1114. [PubMed: 21533017]

35. Calin GA, Croce CM. MicroRNA-cancer connection: the beginning of a new tale. Cancer Res. 2006; 66:7390-4. [PubMed: 16885332]

36. Felicetti F, Errico MC, Bottero L, Segnalini P, Stoppacciaro A, Biffoni M, et al. The promyelocytic leukemia zinc finger-microRNA-221/-222 pathway controls melanoma progression through multiple oncogenic mechanisms. Cancer Res. 2008; 68:2745-54. [PubMed: 18417445] 
37. Gaziel-Sovran A, Segura MF, Di Micco R, Collins MK, Hanniford D, Vega-Saenz de Miera E, et al. miR-30b/30d regulation of GalNAc transferases enhances invasion and immunosuppression during metastasis. Cancer Cell. 2011; 20:104-18. [PubMed: 21741600]

38. Fabbri M, Garzon R, Cimmino A, Liu Z, Zanesi N, Callegari E, et al. MicroRNA-29 family reverts aberrant methylation in lung cancer by targeting DNA methyltransferases $3 \mathrm{~A}$ and 3B. Proc Natl Acad Sci U S A. 2007; 104:15805-10. [PubMed: 17890317]

39. Grignol V, Fairchild ET, Zimmerer JM, Lesinski GB, Walker MJ, Magro CM, et al. miR-21 and miR-155 are associated with mitotic activity and lesion depth of borderline melanocytic lesions. $\mathrm{Br}$ J Cancer. 2011; 105:1023-9. [PubMed: 21863027]

40. Mazar J, DeBlasio D, Govindarajan SS, Zhang S, Perera RJ. Epigenetic regulation of microRNA-375 and its role in melanoma development in humans. FEBS Lett. 2011; 585:2467-76. [PubMed: 21723283]

41. Lujambio A, Calin GA, Villanueva A, Ropero S, Sanchez-Cespedes M, Blanco D, et al. A microRNA DNA methylation signature for human cancer metastasis. Proc Natl Acad Sci U S A. 2008; 105:13556-61. [PubMed: 18768788]

42. Mazar J, Khaitan D, DeBlasio D, Zhong C, Govindarajan SS, Kopanathi S, et al. Epigenetic regulation of microRNA genes and the role of miR-34b in cell invasion and motility in human melanoma. PLoS One. 2011; 6:e24922. [PubMed: 21949788]

43. Young AL, Malik HZ, Abu-Hilal M, Guthrie JA, Wyatt J, Prasad KR, et al. Large hepatocellular carcinoma: time to stop preoperative biopsy. J Am Coll Surg. 2007; 205:453-62. [PubMed: 17765162]

44. Corcoran NM, Hovens CM, Hong MK, Pedersen J, Casey RG, Connolly S, et al. Underestimation of Gleason score at prostate biopsy reflects sampling error in lower volume tumours. BJU Int. 2011

45. Ho AS, Huang X, Cao H, Christman-Skieller C, Bennewith K, Le QT, et al. Circulating miR-210 as a Novel Hypoxia Marker in Pancreatic Cancer. Transl Oncol. 2010; 3:109-13. [PubMed: 20360935]

46. Mitchell PS, Parkin RK, Kroh EM, Fritz BR, Wyman SK, Pogosova-Agadjanyan EL, et al. Circulating microRNAs as stable blood-based markers for cancer detection. Proc Natl Acad Sci U S A. 2008; 105:10513-8. [PubMed: 18663219]

47. Asaga S, Kuo C, Nguyen T, Terpenning M, Giuliano AE, Hoon DS. Direct serum assay for microRNA-21 concentrations in early and advanced breast cancer. Clin Chem. 2011; 57:84-91. [PubMed: 21036945]

48. Heneghan HM, Miller N, Lowery AJ, Sweeney KJ, Newell J, Kerin MJ. Circulating microRNAs as novel minimally invasive biomarkers for breast cancer. Ann Surg. 2010; 251:499-505. [PubMed: 20134314]

49. Ng EK, Chong WW, Jin H, Lam EK, Shin VY, Yu J, et al. Differential expression of microRNAs in plasma of patients with colorectal cancer: a potential marker for colorectal cancer screening. Gut. 2009; 58:1375-81. [PubMed: 19201770]

50. Chen X, Ba Y, Ma L, Cai X, Yin Y, Wang K, et al. Characterization of microRNAs in serum: a novel class of biomarkers for diagnosis of cancer and other diseases. Cell Res. 2008; 18:997-1006. [PubMed: 18766170]

51. Lawrie CH, Gal S, Dunlop HM, Pushkaran B, Liggins AP, Pulford K, et al. Detection of elevated levels of tumour-associated microRNAs in serum of patients with diffuse large B-cell lymphoma. Br J Haematol. 2008; 141:672-5. [PubMed: 18318758]

52. Kanemaru H, Fukushima S, Yamashita J, Honda N, Oyama R, Kakimoto A, et al. The circulating microRNA-221 level in patients with malignant melanoma as a new tumor marker. J Dermatol Sci. 2011; 61:187-93. [PubMed: 21273047]

53. Fu SW, Chen L, Man YG. miRNA Biomarkers in Breast Cancer Detection and Management. J Cancer. 2011; 2:116-22. [PubMed: 21479130]

54. Git A, Dvinge H, Salmon-Divon M, Osborne M, Kutter C, Hadfield J, et al. Systematic comparison of microarray profiling, real-time PCR, and next-generation sequencing technologies for measuring differential microRNA expression. RNA. 2010; 16:991-1006. [PubMed: 20360395] 
55. de Planell-Saguer M, Rodicio MC. Analytical aspects of microRNA in diagnostics: a review. Anal Chim Acta. 2011; 699:134-52. [PubMed: 21704768]

56. Greenberg E, Hershkovitz L, Itzhaki O, Hajdu S, Nemlich Y, Ortenberg R, et al. Regulation of cancer aggressive features in melanoma cells by microRNAs. PLoS One. 2011; 6:e18936. [PubMed: 21541354]

57. Philippidou D, Schmitt M, Moser D, Margue C, Nazarov PV, Muller A, et al. Signatures of microRNAs and selected microRNA target genes in human melanoma. Cancer Res. 2010; 70:4163-73. [PubMed: 20442294]

58. Kroh EM, Parkin RK, Mitchell PS, Tewari M. Analysis of circulating microRNA biomarkers in plasma and serum using quantitative reverse transcription-PCR (qRT-PCR). Methods. 2010; 50:298-301. [PubMed: 20146939]

59. Hunter MP, Ismail N, Zhang X, Aguda BD, Lee EJ, Yu L, et al. Detection of microRNA expression in human peripheral blood microvesicles. PLoS One. 2008; 3:e3694. [PubMed: 19002258]

60. Kondo Y. Epigenetic cross-talk between DNA methylation and histone modifications in human cancers. Yonsei Med J. 2009; 50:455-63. [PubMed: 19718392]

61. Kouzarides T. Chromatin modifications and their function. Cell. 2007; 128:693-705. [PubMed: 17320507]

62. Liang G, Lin JC, Wei V, Yoo C, Cheng JC, Nguyen CT, et al. Distinct localization of histone H3 acetylation and $\mathrm{H} 3-\mathrm{K} 4$ methylation to the transcription start sites in the human genome. Proc Natl Acad Sci U S A. 2004; 101:7357-62. [PubMed: 15123803]

63. Ausio J, Abbott DW. The many tales of a tail: carboxyl-terminal tail heterogeneity specializes histone H2A variants for defined chromatin function. Biochemistry. 2002; 41:5945-9. [PubMed: 11993987]

64. Bonenfant D, Coulot M, Towbin H, Schindler P, van Oostrum J. Characterization of histone H2A and $\mathrm{H} 2 \mathrm{~B}$ variants and their post-translational modifications by mass spectrometry. Mol Cell Proteomics. 2006; 5:541-52. [PubMed: 16319397]

65. Willis-Martinez D, Richards HW, Timchenko NA, Medrano EE. Role of HDAC1 in senescence, aging, and cancer. Exp Gerontol. 2010; 45:279-85. [PubMed: 19818845]

66. Bachmann IM, Halvorsen OJ, Collett K, Stefansson IM, Straume O, Haukaas SA, et al. EZH2 expression is associated with high proliferation rate and aggressive tumor subgroups in cutaneous melanoma and cancers of the endometrium, prostate, and breast. J Clin Oncol. 2006; 24:268-73. [PubMed: 16330673]

67. Zheng H, Gao L, Feng Y, Yuan L, Zhao H, Cornelius LA. Down-regulation of Rap1GAP via promoter hypermethylation promotes melanoma cell proliferation, survival, and migration. Cancer Res. 2009; 69:449-57. [PubMed: 19147557]

68. Fan T, Jiang S, Chung N, Alikhan A, Ni C, Lee CC, et al. EZH2-dependent suppression of a cellular senescence phenotype in melanoma cells by inhibition of $\mathrm{p} 21 / \mathrm{CDKN} 1 \mathrm{~A}$ expression. Mol Cancer Res. 2011; 9:418-29. [PubMed: 21383005]

69. Bandyopadhyay D, Okan NA, Bales E, Nascimento L, Cole PA, Medrano EE. Down-regulation of p300/CBP histone acetyltransferase activates a senescence checkpoint in human melanocytes. Cancer Res. 2002; 62:6231-9. [PubMed: 12414652]

70. Florenes VA, Skrede M, Jorgensen K, Nesland JM. Deacetylase inhibition in malignant melanomas: impact on cell cycle regulation and survival. Melanoma Res. 2004; 14:173-81. [PubMed: 15179185]

71. Hauschild A, Trefzer U, Garbe C, Kaehler KC, Ugurel S, Kiecker F, et al. Multicenter phase II trial of the histone deacetylase inhibitor pyridylmethyl-N-\{4-[(2-aminophenyl)-carbamoyl]-benzyl $\}$ carbamate in pretreated metastatic melanoma. Melanoma Res. 2008; 18:274-8. [PubMed: 18626312]

72. Schoppee Bortz PD, Wamhoff BR. Chromatin Immunoprecipitation (ChIP): Revisiting the Efficacy of Sample Preparation, Sonication, Quantification of Sheared DNA, and Analysis via PCR. PLoS One. 2011; 6:e26015. [PubMed: 22046253]

73. Hardesty WM, Kelley MC, Mi D, Low RL, Caprioli RM. Protein signatures for survival and recurrence in metastatic melanoma. J Proteomics. 2011; 74:1002-14. [PubMed: 21549228] 
74. Esteller M. Epigenetic changes in cancer. F1000 Biol Rep. 2011; 3:9. [PubMed: 21655338]

75. American Cancer Society. Cancer Facts \& Figures 2010. American Cancer Society; Atlanta: 2010.

76. Goldberg M, Rummelt C, Laerm A, Helmbold P, Holbach LM, Ballhausen WG. Epigenetic silencing contributes to frequent loss of the fragile histidine triad tumour suppressor in basal cell carcinomas. Br J Dermatol. 2006; 155:1154-8. [PubMed: 17107382]

77. Heitzer E, Bambach I, Dandachi N, Horn M, Wolf P. PTCH promoter methylation at low level in sporadic basal cell carcinoma analysed by three different approaches. Exp Dermatol. 2010; 19:926-8. [PubMed: 20849535]

78. Bradford PT, Devesa SS, Anderson WF, Toro JR. Cutaneous lymphoma incidence patterns in the United States: a population-based study of 3884 cases. Blood. 2009; 113:5064-73. [PubMed: 19279331]

79. van Doorn R, Zoutman WH, Dijkman R, de Menezes RX, Commandeur S, Mulder AA, et al. Epigenetic profiling of cutaneous T-cell lymphoma: promoter hypermethylation of multiple tumor suppressor genes including BCL7a, PTPRG, and p73. J Clin Oncol. 2005; 23:3886-96. [PubMed: 15897551]

80. Jones CL, Wain EM, Chu CC, Tosi I, Foster R, McKenzie RC, et al. Downregulation of Fas gene expression in Sezary syndrome is associated with promoter hypermethylation. J Invest Dermatol. 2010; 130:1116-25. [PubMed: 19759548]

81. Wu J, Wood GS. Reduction of Fas/CD95 promoter methylation, upregulation of Fas protein, and enhancement of sensitivity to apoptosis in cutaneous T-cell lymphoma. Arch Dermatol. 2010; 147:443-9. [PubMed: 21173302]

82. Duprat JP, Landman G, Salvajoli JV, Brechtbuhl ER. A review of the epidemiology and treatment of Merkel cell carcinoma. Clinics (Sao Paulo). 2011; 66:1817-23. [PubMed: 22012057]

83. Lassacher A, Heitzer E, Kerl H, Wolf P. p14ARF hypermethylation is common but INK4a-ARF locus or p53 mutations are rare in Merkel cell carcinoma. J Invest Dermatol. 2008; 128:1788-96. [PubMed: 18219279]

84. McShane LM, Altman DG, Sauerbrei W, Taube SE, Gion M, Clark GM. REporting recommendations for tumor MARKer prognostic studies (REMARK). Nat Clin Pract Oncol. 2005; 2:416-22. [PubMed: 16130938]

85. Bustin SA, Benes V, Garson JA, Hellemans J, Huggett J, Kubista M, et al. The MIQE guidelines: minimum information for publication of quantitative real-time PCR experiments. Clin Chem. 2009; 55:611-22. [PubMed: 19246619]

86. Penna E, Orso F, Cimino D, Tenaglia E, Lembo A, Quaglino E, et al. microRNA-214 contributes to melanoma tumour progression through suppression of TFAP2C. EMBO J. 2011; 30:1990-2007. [PubMed: 21468029]

87. Dar AA, Majid S, de Semir D, Nosrati M, Bezrookove V, Kashani-Sabet M. miRNA-205 suppresses melanoma cell proliferation and induces senescence via regulation of E2F1 protein. $\mathrm{J}$ Biol Chem. 2011; 286:16606-14. [PubMed: 21454583]

88. Streicher KL, Zhu W, Lehmann KP, Georgantas RW, Morehouse CA, Brohawn P, et al. A novel oncogenic role for the miRNA-506-514 cluster in initiating melanocyte transformation and promoting melanoma growth. Oncogene. 2011

89. Calin GA, Croce CM. MicroRNA signatures in human cancers. Nat Rev Cancer. 2006; 6:857-66. [PubMed: 17060945]

90. Howell PM Jr, Li X, Riker AI, Xi Y. MicroRNA in Melanoma. Ochsner J. 2010; 10:83-92. [PubMed: 21603362]

91. Mueller DW, Bosserhoff AK. Role of miRNAs in the progression of malignant melanoma. Br J Cancer. 2009; 101:551-6. [PubMed: 19638982]

92. Mueller DW, Bosserhoff AK. The evolving concept of 'melano-miRs'-microRNAs in melanomagenesis. Pigment Cell Melanoma Res. 2010; 23:620-6. [PubMed: 20557479]

93. Richards HW, Medrano EE. Epigenetic marks in melanoma. Pigment Cell Melanoma Res. 2009; 22:14-29. [PubMed: 19040501] 


\section{Cutaneous Melanoma \\ Epigenomic Biomarkers}

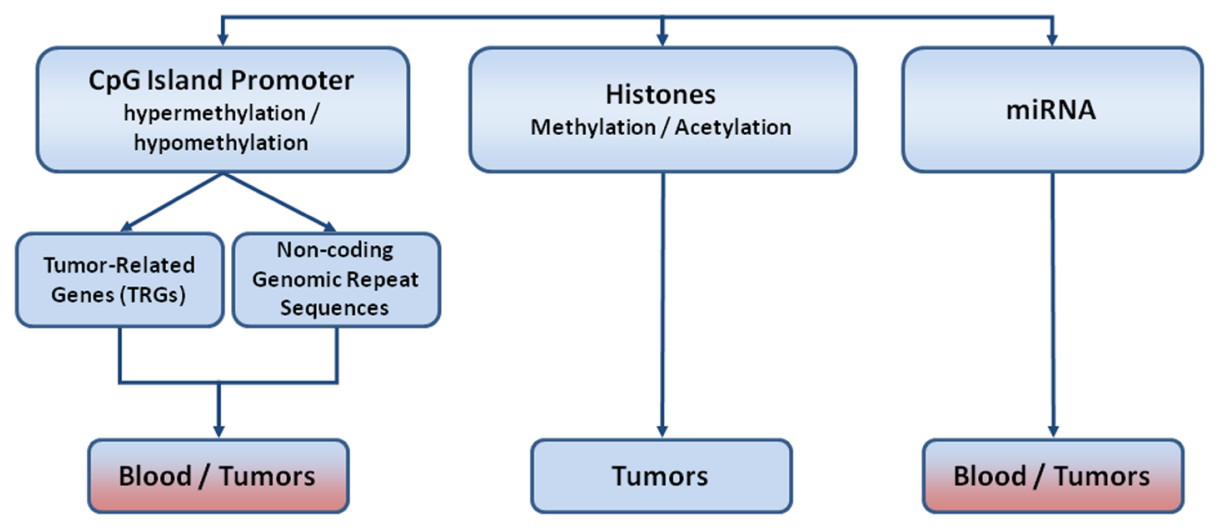

Figure 1.

Epigenomic BMs and studied applications. 

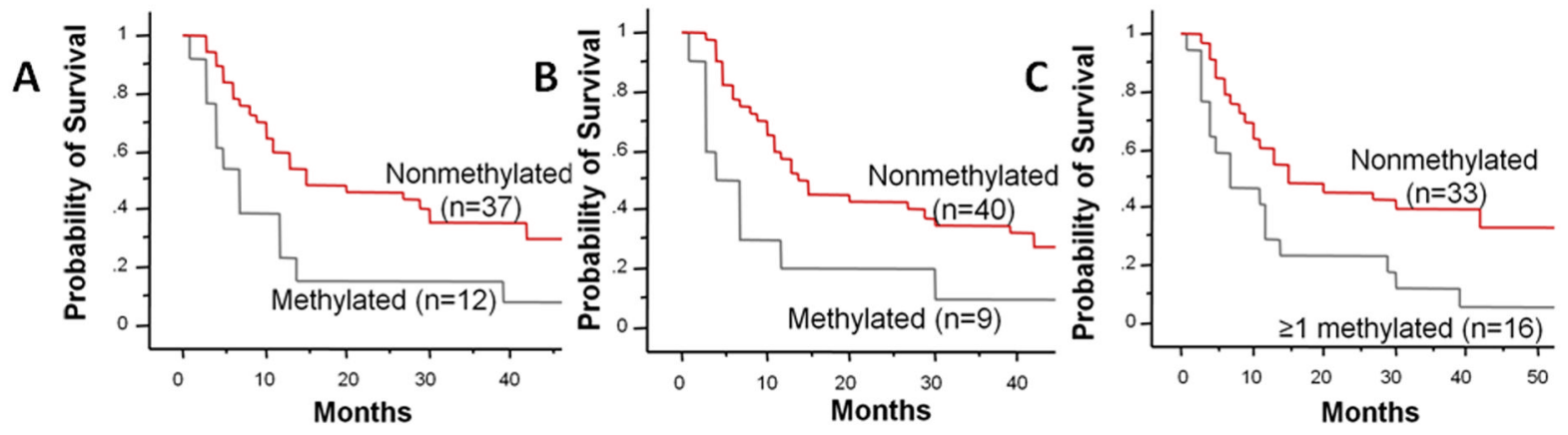

Figure 2.

(A) Kaplan-Meier survival curves of biochemotherapy (BC) patients: Correlation of pre-BC serum RASSF1A methylation BM with overall survival (log-rank test, $\mathrm{P}=.013$ ).

Methylated: Patients with serum methylation of RASSF1A. Nonmethylated: Patients with no serum methylation of RASSF1A. (B) Correlation of pre-BC serum RAR $\beta-2$ methylation status with overall survival (log-rank test, $\mathrm{P}=.02)$. Methylated: Patients with serum methylation of RAR $\beta-2$. Nonmethylated: Patients with no serum methylation of RAR $\beta-2$.

(C) Correlation of pre-BC serum methylation of at least one BM with overall survival (logrank test, $\mathrm{P}=.01)$. $\geq 1$ methylated: Patients with serum methylation of at least one BM. Nonmethylated: Patients with no serum methylation of genes. Figure reproduced with permission from Mori et al. 2005 [28]. 

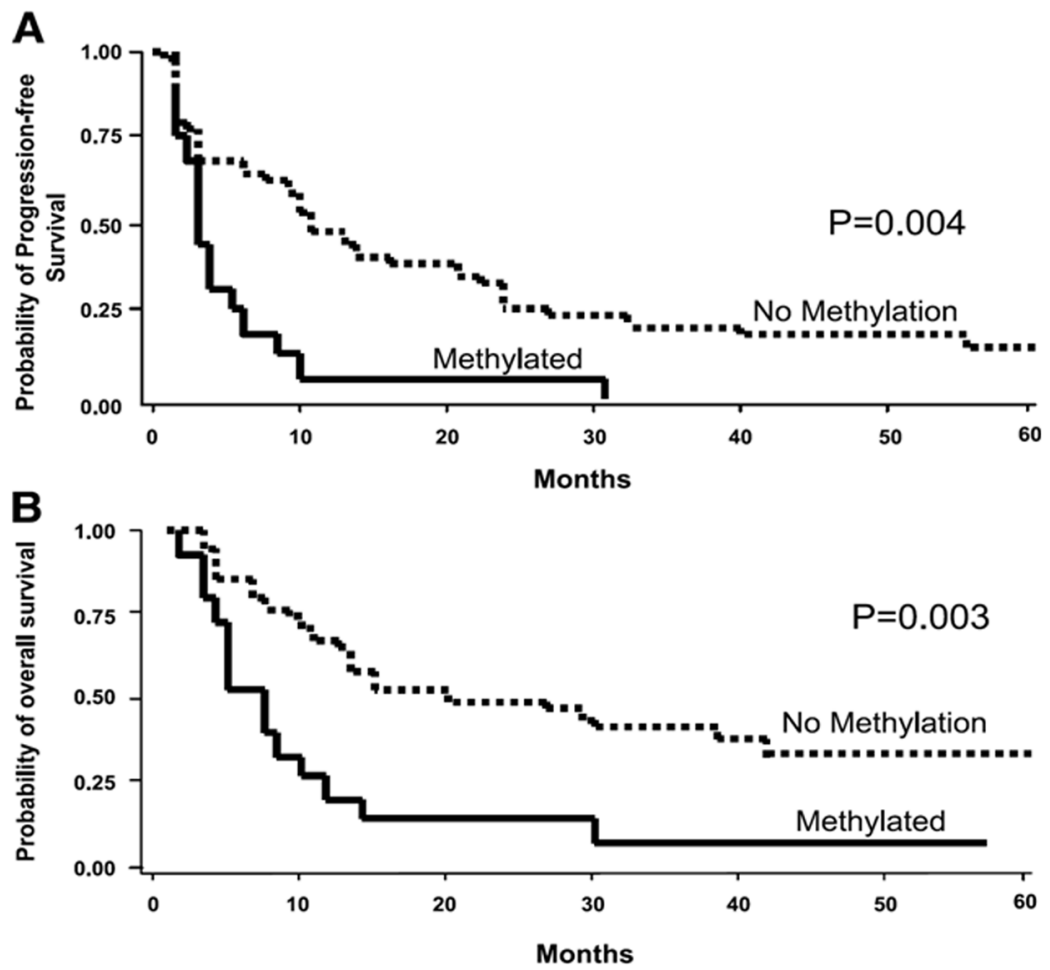

Figure 3.

(A) Kaplan-Meier curves showing the correlation of pre-BC serum ER-a methylation status with progression-free survival (Cox proportional hazard, $\mathrm{P}=0.004$ ). Methylated, patients with serum methylated ER-a DNA. No methylation, patients with no detectable serum methylated ER-a. (B) Kaplan-Meier curves showing the correlation of pre-biochemotherapy serum ER-a methylation status with OS (Cox proportional hazard, $\mathrm{P}=0.003$ ). Figure reproduced with permission from Mori et al. 2006 [10]. 


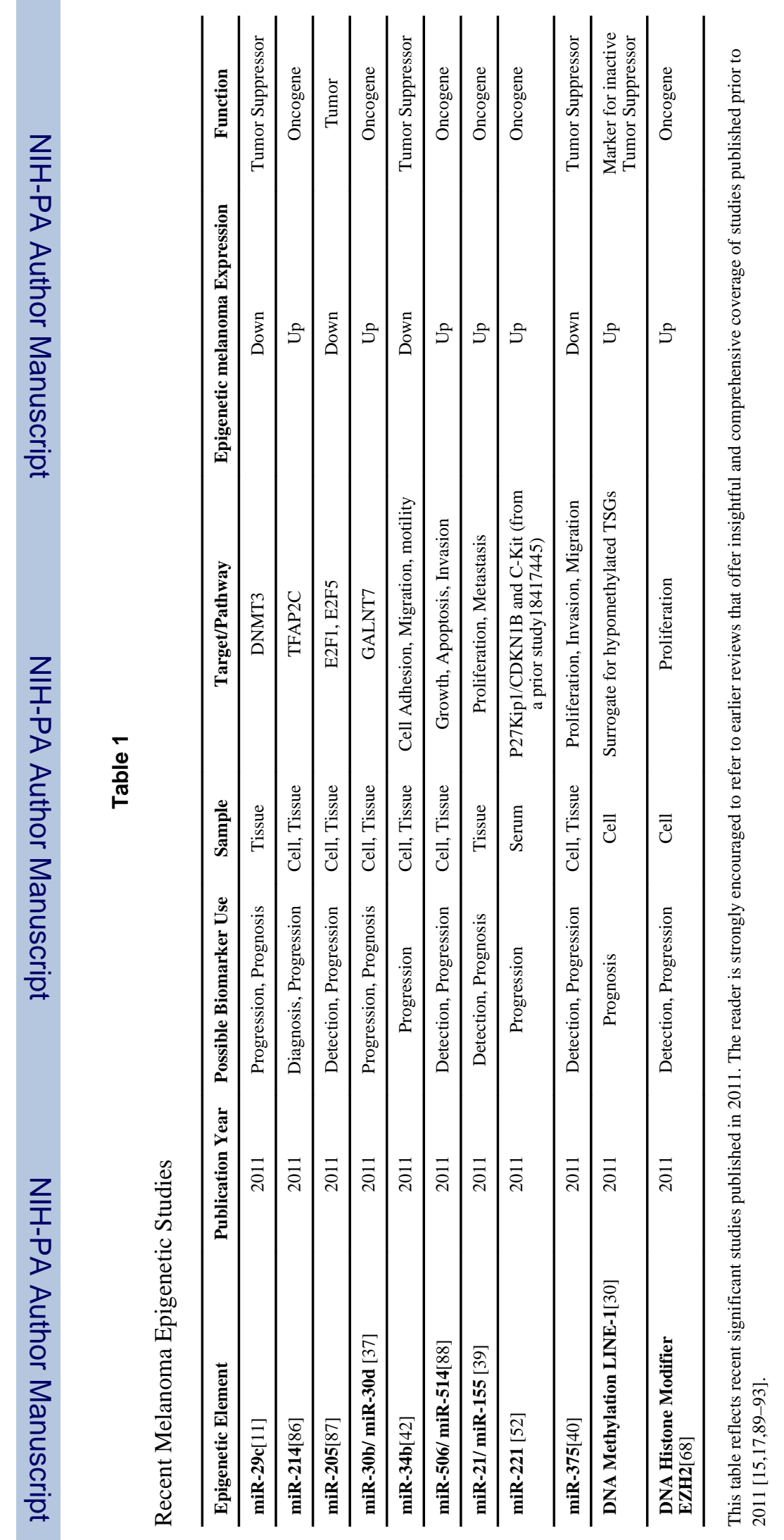

